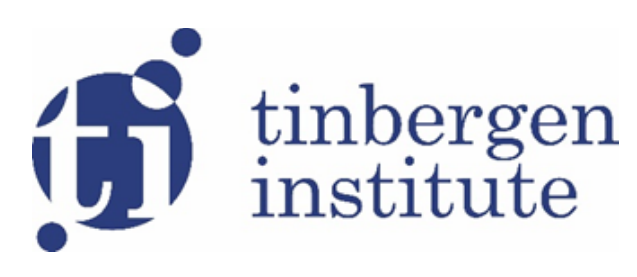

TI 2020-027/VIII

Tinbergen Institute Discussion Paper

\title{
Risk attitude and air pollution: Evidence from chess*
}

Joris Klingen ${ }^{1}$

Jos van Ommeren ${ }^{1}$

${ }^{1}$ Vrije Universiteit Amsterdam and Tinbergen Institute Amsterdam 
Tinbergen Institute is the graduate school and research institute in economics of Erasmus University Rotterdam, the University of Amsterdam and Vrije Universiteit Amsterdam.

Contact: discussionpapers@tinbergen.nl

More TI discussion papers can be downloaded at https://www.tinbergen.nl

Tinbergen Institute has two locations:

Tinbergen Institute Amsterdam

Gustav Mahlerplein 117

1082 MS Amsterdam

The Netherlands

Tel.: +31(0)205984580

Tinbergen Institute Rotterdam

Burg. Oudlaan 50

3062 PA Rotterdam

The Netherlands

Tel.: +31(0)10408 8900 


\title{
Risk ATTITUDE AND AIR POLLUTION: EVIDENCE FROM CHESS*
}

\author{
Joris Klingen $^{\dagger} \quad$ Jos van Ommeren ${ }^{\ddagger}$
}

May 20, 2020

\begin{abstract}
Medical research suggests that particulate matter (PM) increases stress hormones, therefore increasing the feeling of stress, which has been hypothesised to induce individuals to take less risk. To examine this, we study whether PM increases the probability of drawing in chess games using information from the Dutch club competition. We provide evidence of a reasonably strong effect: A $10 \mu \mathrm{g}$ increase in $\mathrm{PM}_{10}$ (33.6\% of mean concentration) leads to a $5.8 \%$ increase in draws. Our results demonstrate that air pollution causes individuals to take less risk.
\end{abstract}

Keywords: air pollution, particulate matter, cognitive ability, risk taking JEL Codes: D81, I18, J24, Q53

${ }^{*}$ We would like to thank Koos Stolk of the Royal Dutch Chess Federation for help with the data. Moreover we would like to thank Hans Koster, Erik Verhoef, Francis Ostermeijer, Devi Brands, Jesper de Groote, and seminar participants at University of Birmingham and VU Amsterdam.

${ }^{\dagger}$ Corresponding author. Email: j.j.klingen@vu.nl. Vrije Universiteit Amsterdam, De Boelelaan 1105, 1081 HV Amsterdam, The Netherlands, and Tinbergen Institute Amsterdam. Gustav Mahlerplein 1171082 MS Amsterdam, The Netherlands.

${ }_{\ddagger}^{\ddagger}$ Email: jos.van.ommeren@vu.nl. Vrije Universiteit Amsterdam, De Boelelaan 1105, 1081 HV Amsterdam, The Netherlands, and Tinbergen Institute Amsterdam (fellow). Gustav Mahlerplein 1171082 MS Amsterdam, The Netherlands. 


\section{Introduction}

Particulate matter (PM) is found to increase stress hormones and blood pressure, therefore increasing the feeling of stress, which has been hypothesised to induce individuals to take less risk than is rational (Duflo and Banerjee, 2011). ${ }^{1}$ To examine this, we study the effect of PM on risk outcomes of the game of chess, i.e. the probability to make a draw.

The literature mainly focuses on long-term health effects of PM and other air pollution (see e.g. Chappie and Lave, 1982 and Beach and Hanlon, 2018). In contrast, we focus on the immediate effect of air pollution, for which there is growing attention (Graff Zivin and Neidell, 2018). We now know that pollution also has an immediate detrimental effect on physical health and therefore on economic and social activities which depend on physical health (e.g. labour productivity, cycling to work). ${ }^{2}$

It is less well-known that the immediate effects of PM are more subtle and widespread. PM affects cognitive ability, and therefore reasoned judgement and decision-making (see e.g. Hamanaka and Mutlu, 2018). Medical studies show that PM increases stress hormones (such as cortisol) as well as blood pressure (Li et al., 2017; Barbosa et al., 2012). In other contexts, PM negatively affects important activities which require cognitive performance, including educational achievement (Ebenstein et al., 2016), high skill work (Kahn and Li, 2019) and investment decisions (Huang et al., 2017). Traders on Wall Street have lower returns on days with higher level of PM (Heyes et al., 2016), while baseball referees underperform given higher levels of PM (Archsmith et al., 2018). ${ }^{3}$

\footnotetext{
${ }^{1}$ Duflo and Banerjee (2011) observe that poorer individuals have more stress and make irrational investment decisions.

${ }^{2}$ Graff Zivin and Neidell (2012) show that agricultural workers are less productive on days with high ozone levels. Lichter et al. (2017) identify a small effect of PM on some productivity indicators of professional players in football. Chang et al. (2016), Chang et al. (2019) study productivity of pear packers and call centre employees and find adverse effects of PM pollution on productivity. Klingen and van Ommeren (2020) show that ozone reduces cycling speed.

${ }^{3}$ Künn et al. (2019) report that cognitive performance of chess players deteriorate due to PM, but as the latter is measured on a limited number of days, it is unclear whether this result generally holds.
} 
A number of recent studies show individuals' decision-making effects of PM that point at the possibility that PM reduces risk-taking (Lu, 2019). For example, Heyes et al. (2016) argue that one possible interpretation of their findings for lower returns for Wall Street traders is that PM induces these traders to take less risk. ${ }^{4}$ This is in line with papers on PM and crime that suggest that anxiety increases with PM. (Herrnstadt et al., 2016; Burkhardt et al., 2019). There is also evidence that daily higher PM levels increase the probability of buying health insurance (Chang et al., 2018), and reduce the sales of lottery tickets (Bondy et al., 2019). ${ }^{5}$

These studies estimate PM effects that are likely the result of several behavioural factors (notably skills, discounting, and risk taking). It is still unclear which behavioural mechanisms underlie previous findings. More specifically, we do not know whether PM affects decision making. In contrast to existing studies, we study the effect of PM on an indicator of risk taking, using the game of chess. Thereby, we can provide conclusive field evidence on the often stated hypothesis that PM air pollution induces individuals to take less risk (than is rational).

Risk-taking is essential to the game of chess. The main advantage of focusing on chess is that it offers a direct measure of risk: the variance of game outcomes reflects risk-taking, as many games end in a draw. Furthermore, the time horizon of a chess game is short (a few hours), so estimates are not affected by the effects of PM on discount rates or projection bias (Heyes et al., 2016; Bondy et al., 2019). Consequently, the effect of PM on risk-taking can be examined by analysing its effect on the probability of making a draw.

\footnotetext{
${ }^{4}$ An alternative explanation is that these traders lose or adapt their discount rate. Furthermore, Chew et al. (2019) also suggest that PM makes individuals more risk averse. PM increases car accidents (Sager, 2019) as well as crime (Bondy et al., 2019), but these studies show that these results are unlikely due to higher levels of risk-taking.

${ }^{5}$ The benefits of health insurance and lottery gains are in the future, so an alternative explanation is that PM affects the discount rate. Projections bias may also play a role. Projection bias is the tendency for individuals to exaggerate the degree to which their future tastes will resemble current tastes, which is likely affected by pollution.
} 
The ideal experimental setup to estimate the causal effect of pollution on the probability to make a draw, is to examine the outcome of games of players that are randomly assigned to play against each other at different locations with different levels of pollution. We come close to that setup by analysing games played in the Dutch team club competitions, where teams belonging to the same league play at different locations and all teams play each other (as is common in most national team sports competitions). ${ }^{6}$ In addition, all games take place at the same time (on Saturdays at $1 \mathrm{pm}$ ), and are scheduled in advance, so that our results are not driven by any extensive margin decisions, as would for example be the case for online chess games. Because pollution levels do not vary randomly over time and space, we control for time-specific as well as location-specific unobserved factors using a fixed effects strategy. ${ }^{7}$

In our estimation approach, we pay special attention to measurement error in PM due to the distance between the pollution monitor and the chess location. Measurement error in pollution levels usually causes attenuation bias. One way to deal with this is to use instrumental variables, which is the preferred strategy in the literature. In particular, it is common to use temperature inversion as an instrument (Jans et al., 2018). Although this strategy is attractive, there are also disadvantages with its use. ${ }^{8}$ We follow a different route. We focus on chess locations close to PM monitoring stations. Furthermore, we will show how the PM effects decrease with distance to the pollution monitor.

We pay special attention to the alternative hypothesis that PM negatively affects the cognitive performance of chess players, and therefore affects the probability of making a draw. We show that this alternative hypothesis does not hold by demonstrating that weaker

\footnotetext{
${ }^{6}$ For that reason, we concentrate on the Dutch national competition, but ignore information from other countries (e.g. Germany, UK), where players tend to play at the same location, hence there is little or no spatial variation.

${ }^{7}$ The probability of a draw depends on the strength of the players. Therefore, we can improve the efficiency of our estimates by controlling for Elo rating, which measures time-varying player strength (Regan and Haworth, 2011).

${ }^{8}$ It is plausible that the instrument affects a range of pollutions, and not only PM, so it is difficult to interpret the IV estimate as a causal estimate of PM. In addition, confidence intervals of the IV estimates are much larger (and tend not to differ from OLS estimates using Hausman tests).
} 
players make fewer draws, which implies that reduced cognitive performance can only induce a negligible downward bias.

In conclusion, we will provide evidence that $\mathrm{PM}_{10}$ reduces risk-taking. ${ }^{9} \mathrm{~A} 10 \mu \mathrm{g}$ increase in $\mathrm{PM}_{10}$ (33.6\% of mean concentration) leads to a $5.8 \%$ increase in draws. We do not find any effect of PM when measured at the location of the visiting club, or of effects of PM on previous days, which implies that the PM effect is immediate. This finding supports and complements other studies that show the effect of pollution on decision taking, but which offer several explanations to explain their findings or projection bias (Heyes et al., 2016; Bondy et al., 2019).

This paper proceeds as follows. Section 2 explains the methods employed. Section 3 describes the data and descriptive statistics. Section 4 presents results. Section 5 concludes.

\section{Empirical method}

\subsection{Identification}

Chess is a zero-sum perfect information game between two players, with two possible outcomes: either one of the players wins, or there is a draw. Chess players have a strong influence on the level of risk they take (these determinants are discussed later on). ${ }^{10}$

In the (financial and economics) literature on risk-taking, a common measure of risktaking outcomes is the standard deviation (e.g. the standard deviation of the return of a portfolio), and therefore the outcome variance. The variance of chess outcomes is a one-to-

\footnotetext{
${ }^{9}$ We use a daily measure of $\mathrm{PM}_{10}$ rather than a measure of $\mathrm{PM}_{2.5}$ observed during the game, which may be a slightly better measure from a theoretical point of view. However, $\mathrm{PM}_{2.5}$ is roughly $1 / 30$ of the diameter of a human hair, it may go through walls, and as result outside and inside concentration levels are usually the same. We observe the latter only for a short period. This is not problematic, as the attenuation bias of using $\mathrm{PM}_{10}$ rather than $\mathrm{PM}_{2.5}$ is small, as the correlation between those two measures is 0.90 .

${ }^{10}$ For example, players choose between safe and risky openings, which affects the probability of a draw. Players can also choose risky moves, i.e. moves that reduce the probability of a draw. Players are categorised as with a risk attitude (e.g., the 1985-2000 world champion Kasparov) or with a less risky attitude (e.g., the 1963-1969 world champion Petrosian).
} 
one linear negative function of the proportion of draws. ${ }^{11}$ Let $D_{i c t}$ be a dummy indicator of whether a game $i$ in location $c$ on day $t$ ends in a draw. The level of PM in location $c$ on day $t$ is denoted by $P M_{c t}$. We aim to estimate the causal effect of $P M_{c t}$ on $D_{i c t}$ using a linear probability model.

The first main econometric issue when aiming to estimate a causal effect of PM on the probability of a draw, is that PM does not randomly vary over time, but there are strong time trends in levels of PM (as air pollution tends to decrease over this time). Furthermore, PM is not randomly allocated across space but is concentrated in certain cities. It is also possible that certain cities attract players with different propensities of making a draw.

The ideal way to address these issues is to compare outcome of games of players that are randomly allocated to other players at different locations for different time periods. By using the universe of chess games of a national competition for longer periods, combined with a day and location fixed effect regression design, we approach this ideal setup. In the national competition, players play half of all games at their home location and the other half at another location. Hence, in essence, we use variation in PM at different locations within the same day. For reasons of efficiency, we include two game-specific control variables: the difference in ELO rating between the players, as well as the average rating of the players. ${ }^{12}$ We will control for weather conditions that potentially confound the effect of PM, as studies such as Wang (2017) and Heyes and Saberian (2019) show that temperature has an effect on decision making.

Consequently, we will estimate the following fixed-effects regression:

$$
D_{i c t}=\alpha_{c}+\alpha_{t}+\beta \cdot P M_{c t}+\gamma \cdot \mathbf{X}_{i c t}+\delta \cdot z_{c t}+\varepsilon_{i c t}
$$

where $\alpha_{c}$ and $\alpha_{t}$ denote location and day fixed effects. Here, $\mathbf{X}_{i c t}$ denotes control vari-

\footnotetext{
${ }^{11}$ The outcome variance is equal to (1 - proportion of draws)/4.

${ }^{12} \mathrm{It}$ is straightforward to show that this specification implies that we control for the rating of the strongest player and the rating of the weakest player, where we allow the effects of these variables to differ.
} 
ables that capture players' strength and $z_{c t}$ denotes (time-varying) location-specific control variables, such as weather conditions.

We have not yet been specific about the type of location fixed effects used. To elaborate on this, we use three types of location fixed effects. We use one fixed effect for the club of the home player, one fixed effect for the club of the visitor player, and one fixed effect for the PM monitor. In the analysis, we will cluster the standard errors at the level of the PM monitor as well as day $t$.

One of the strengths of the design is that we will see that inclusion of the location fixed effects as well as the weather control variables does not affect the results, which makes it more plausible that the variation in PM is exogenous. ${ }^{13}$ This also makes sense, as the Netherlands is a geographically small country, hence the distance between these locations is small (the average distance is only $70 \mathrm{~km}$, where we weigh by number of games per location). ${ }^{14}$ Hence, by including day fixed effects, we already almost perfectly control for differences in weather conditions (e.g. differences in temperature and sunshine are negligible).

The second econometric issue is that PM reduces the ability of players to play well, resulting in more mistakes (Ebenstein et al., 2016; Künn et al., 2019). This does not imply that this will induce more draws. An important feature of chess, for which we will provide ample evidence, is that the probability of making a draw is a non-decreasing function of players' ability level. Even better, we show that the probability to make a draw does not depend on the level of the player, except for very strong players (who are rare in our dataset) who make more draws. ${ }^{15}$ Hence, the effect of PM on the probability of draws through its effect on ability is negligible. Furthermore, we will demonstrate that even if we assume that

\footnotetext{
${ }^{13}$ Because our results also hold without location fixed effects, our estimates hold with one-way fixed effect models, we do not have the issue that two-way fixed effects models have difficulties addressing heterogeneity of estimates, resulting in inconsistent estimates (de Chaisemartin and d'Haultfoeuille, 2020).

${ }^{14}$ For example, the distance between Amsterdam and Rotterdam, the two largest cities of the Netherlands, is only $65 \mathrm{~km}$, whereas a number of cities, such as the Hague, Delft and Leiden, are located in between.

${ }^{15}$ This makes sense. Stronger players are better able to calculate the consequences of their moves, and therefore have more control over the game outcome.
} 
PM has (unreasonably) large effects on the ability of both players (i.e. an unreasonable large drop in their Elo ratings), then this assumption cannot explain our findings.

The third econometric issue is measurement error, as the spatial density of PM monitor stations is usually rather low, which causes attenuation bias. To avoid this, we use to our advantage that in the Netherlands many chess clubs, and in particular large clubs with many players, are located in larger cities which have several monitoring stations. Subsequently, we will focus on chess games within a maximum distance of $5 \mathrm{~km}$ of a monitoring station, so the average distance between the chess location and the monitoring station is small and slightly more than $2 \mathrm{~km}$. In our sensitivity analysis, we will show that increasing the maximum distance indeed results in lower, but still statistically significant, estimates, whereas reducing the maximum distance results in somewhat higher point estimates but larger confidence intervals. ${ }^{16}$

The fourth econometric issue is whether the effect of PM is dynamic. The medical literature does not answer the question whether the effect of PM is immediate or also with a delay. ${ }^{17}$ The latter is theoretically possible, because PM remains in the blood circulation. For that reason, we will also measure PM on the day before the match, as well as at the location of the visiting club. The idea of the latter PM measure is that chess players typically live close to their club, and hence visitor players might be treated in the night or morning before travelling to the game. As a placebo check, we will additionally examine the effects of PM measured on the day after the game. 


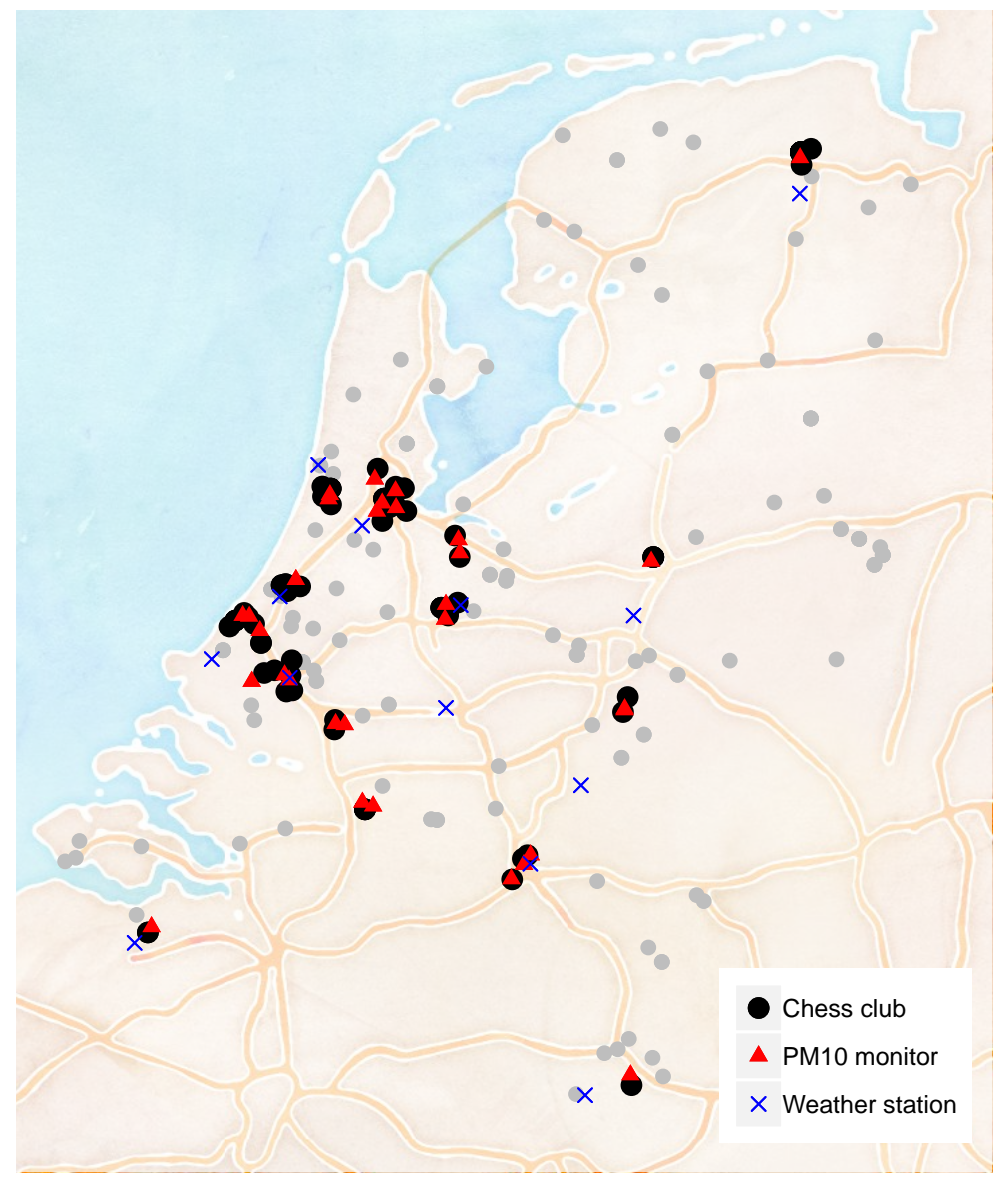

Figure 1: Locations of chess clubs, weather stations and PM monitoring stations.

Notes: Greyed out chess locations are excluded because of a too large distance to PM or weather monitoring stations. Some of these locations are used for sensitivity analyses.

\section{Data}

We observe the universe of outcomes of (classical) chess games for the Dutch national team competition from 2002 until 2018, played at locations as shown on the map in Figure $1 .^{18}$

\footnotetext{
${ }^{16}$ It is not an issue that we do not measure PM inside buildings, as environmental policies use information from outside monitoring stations, so the preferred measures, from a policy point of view, is the measure used by us.

${ }^{17}$ Our main source of effect of PM in this literature is Li et al. (2017). In this study, participants are treated with PM for a number of days, but dynamic treatment effects are not investigated.

${ }^{18}$ The Dutch league follows the rules of the World Chess Federation FIDE: players receive 90 minutes for the first 40 moves, and an additional 30 minutes for the rest of the game. For each move played, the player receives an additional 30 seconds. A player who exceeds the time limit loses the game.
} 
Each year, there are about 15 different leagues, in which between 8 and 10 teams compete. For games played in the highest league, we also observe the moves of the full game. Teams have 8 or 10 players and play either at home or away (similar to, for example, soccer). Although chess players play for a team, individual chess outcomes are relevant for players, as the outcome influences their Elo-rating. A competition year contains 9 rounds, played on Saturday afternoons (from September until May). Typically, there is one month between two consecutive rounds. In a round, each player plays one game (a game takes about 4 hours). ${ }^{19}$

To reduce measurement error in PM measurements, we focus on games within $5 \mathrm{~km}$ of a PM station (we come back to this in the sensitivity analysis). Furthermore, we exclude a limited number of games further than $50 \mathrm{~km}$ of a weather station. We also make another selection, which is not essential, but improves interpretation. To reduce correlation between PM observations measured at the home club and the visitors club, we concentrate on games with a minimum distance between home location and visitors location of $20 \mathrm{~km}$. We also require the presence of a PM station within $20 \mathrm{~km}$ of the visitor club's location. Given these restrictions, the average distance to the PM monitor is slightly above $2 \mathrm{~km}$, hence the distance to the nearest weather station is small and about $11 \mathrm{~km} .{ }^{20}$ The share of draws is 0.32 . The average PM level is about $30 \mu \mathrm{g} / \mathrm{m}^{3}$. Given these restrictions, we have almost 20k games played by 3,326 players at 81 different locations (see Table 1). We do not always observe weather conditions. When we focus on games for which we observe weather conditions, we observe more than 17,000 games for more than 1,000 clusters, defined as unique PM location-day observations.

For each player, we observe the so called Elo rating at the time of playing, which is an

\footnotetext{
${ }^{19}$ When chess clubs have several teams in the national competition, and the team plays at home, then all games are played at the same location.

${ }^{20}$ The correlation between PM measurement stations for a sample with the same average distance as our main sample, is about 0.77 , suggesting that attenuation bias will be about $40 \%$. Here we use the formula $1-\rho^{2}=1-0.77^{2}=0.40$, derived from Cameron and Trivedi (2005), where $\rho$ is the correlation between PM at the measured location and PM at the chess location.
} 
Table 1: Descriptive statistics

\begin{tabular}{lccccc}
\hline \hline Statistic & $\mathrm{N}$ & Mean & St. Dev. & Min & Max \\
\hline Draw & 4,415 & 0.32 & 0.47 & 0.00 & 1.00 \\
Mean rating game (100 points) & 4,415 & 21.06 & 1.56 & 16.80 & 26.26 \\
Abs. rating difference game $(100$ points) & 4,415 & 1.11 & 0.94 & 0.01 & 8.08 \\
Distance to PM monitor $(\mathrm{km})$ & 4,415 & 2.33 & 1.03 & 0.27 & 4.96 \\
Distance to weather station $(\mathrm{km})$ & 4,415 & 10.86 & 6.95 & 0.65 & 36.77 \\
Distance between home and visitors $(\mathrm{km})$ & 4,415 & 68.75 & 43.06 & 20.22 & 266.54 \\
PM10 $\left(10 \mu \mathrm{g} / \mathrm{m}^{3}\right)$ & 4,415 & 2.91 & 1.41 & 0.57 & 13.77 \\
Temperature $(\mathrm{Celsius})$ & 3,897 & 7.71 & 4.72 & -7.80 & 20.10 \\
Radiation $\left(\mathrm{Watt} / \mathrm{m}^{2}\right)$ & 3,897 & 0.68 & 0.54 & 0.02 & 2.32 \\
Air Pressure $(1000 \mathrm{hPa})$ & 3,887 & 1.02 & 0.01 & 0.98 & 1.04 \\
\hline
\end{tabular}

accurate numerical representation of a player's strength (Regan and Haworth, 2011). The average rating is about 2100, with a standard deviation of 157 . Almost all players have a rating between 1800 and 2400. In Figure A1a in the Appendix, we provide the rating distribution. Taking risks may be perceived differently by two players who play a game depending on the difference in strength. Figure A3 shows a histogram of the (absolute) difference in rating as well as the probability that the player with the highest rating will win, draw, or lose. The difference in ratings is usually less than 300 points (less than two standard deviations), and up to that level, the strongest player still has a reasonably high risk of most winning the game.

We use daily $\mathrm{PM}_{10}$ measured at 63 locations provided by Netherlands National Institute for Public Health and the Environment (2019), see Figure 1. In addition we use daily weather observations from Royal Netherlands Meteorological Institute (2019), which include temperature, solar radiation, rain and atmospheric pressure. 
Table 2: Regression results.

\begin{tabular}{|c|c|c|c|c|c|c|}
\hline & \multicolumn{6}{|c|}{ Draw } \\
\hline & $(1)$ & $(2)$ & $(3)$ & $(4)$ & $(5)$ & (6) \\
\hline $\mathrm{PM}_{10}$ & $\begin{array}{c}0.0151^{* * *} \\
(0.0045)\end{array}$ & $\begin{array}{c}0.0183^{* * *} \\
(0.0050)\end{array}$ & $\begin{array}{c}0.0186^{* * *} \\
(0.0051)\end{array}$ & $\begin{array}{c}0.0197^{* * *} \\
(0.0053)\end{array}$ & & $\begin{array}{c}0.0193^{* * *} \\
(0.0064)\end{array}$ \\
\hline $\mathrm{PM}_{10}$ (visitors) & & & $\begin{array}{c}-0.0035 \\
(0.0048)\end{array}$ & $\begin{array}{c}-0.0052 \\
(0.0051)\end{array}$ & & $\begin{array}{c}-0.0037 \\
(0.0067)\end{array}$ \\
\hline $\mathrm{PM}_{10}$ lag & & & & & $\begin{array}{c}0.0121^{*} \\
(0.0062)\end{array}$ & $\begin{array}{c}0.0029 \\
(0.0071)\end{array}$ \\
\hline $\mathrm{PM}_{10}$ lag (visitors) & & & & & $\begin{array}{c}-0.0036 \\
(0.0061)\end{array}$ & $\begin{array}{c}-0.0004 \\
(0.0076)\end{array}$ \\
\hline $\mathrm{PM}_{10}$ lead & & & & & & $\begin{array}{l}-0.0020 \\
(0.0075)\end{array}$ \\
\hline $\mathrm{PM}_{10}$ lead (visitors) & & & & & & $\begin{array}{c}-0.0031 \\
(0.0074)\end{array}$ \\
\hline Mean rating (100 points) & $\begin{array}{c}0.0088^{* * *} \\
(0.0022)\end{array}$ & $\begin{array}{c}0.0081^{* * *} \\
(0.0027)\end{array}$ & $\begin{array}{c}0.0081^{* * *} \\
(0.0027)\end{array}$ & $\begin{array}{c}0.0106^{* * *} \\
(0.0030)\end{array}$ & $\begin{array}{c}0.0107^{* * *} \\
(0.0030)\end{array}$ & $\begin{array}{c}0.0107^{* * *} \\
(0.0030)\end{array}$ \\
\hline Abs. diff. rating (100 points) & $\begin{array}{c}-0.0488^{* * *} \\
(0.0031)\end{array}$ & $\begin{array}{c}-0.0507^{* * *} \\
(0.0033)\end{array}$ & $\begin{array}{c}-0.0507^{\text {*** }} \\
(0.0033)\end{array}$ & $\begin{array}{c}-0.0489^{* * *} \\
(0.0036)\end{array}$ & $\begin{array}{c}-0.0488^{* * *} \\
(0.0036)\end{array}$ & $\begin{array}{c}-0.0489^{* * *} \\
(0.0036)\end{array}$ \\
\hline Loc. \& club FE & & Yes & Yes & Yes & Yes & Yes \\
\hline Weather dummies & & & & Yes & Yes & Yes \\
\hline Time FE & Day & Day & Day & Day & Day & Day \\
\hline Clusters & 1137 & 1137 & 1137 & 1029 & 1028 & 1028 \\
\hline Observations & 19,763 & 19,763 & 19,763 & 17,327 & 17,310 & 17,310 \\
\hline $\mathrm{R}^{2}$ & 0.0172 & 0.0378 & 0.0378 & 0.0432 & 0.0428 & 0.0432 \\
\hline
\end{tabular}

Notes: $\mathrm{PM}_{10}$ variables are rescaled to $10 \mu \mathrm{g} / \mathrm{m}^{3}$. Location fixed effects are at the level of a monitoring station. Club fixed effects contain separate controls for playing at home or as visitor. Robust standard errors in parentheses are clustered at the level of day $\times$ monitoring station. ${ }^{* * *},{ }^{* *},{ }^{*}$ indicate significance at $1 \%, 5 \%$, and $10 \%$.

\section{Results}

\subsection{Main results}

We show in Table 2 the estimated effects of PM on draws for a range of specifications based on equation (1). In specification (1), we show the effect when we control for day fixed effects, the average rating (per game) and the difference between the rating of the players. We find a positive effect of PM. The point estimate is equal to 0.015 (with a standard error of 0.005), which implies that one standard deviation increase in PM increases the probability of a draw 
with 2.4 percentage points. Furthermore, we find a weak (but positive) effect of the mean rating (later on we will see that this effect is entirely due to the games with higher ratings), whereas we find a rather strong effect of the difference in rating.

One criticism of this specification is that it does not control for unobserved characteristics. We deal with this in specification (2), where we include PM locations and club fixed effects. The results become somehow more pronounced. ${ }^{21}$ We have additionally estimated models with player fixed effects. This does not change the estimates (as we control for club fixed effects, and for rating.) Another criticism is that it may provide an underestimate of the overall effect of PM, because visitors are treated for a shorter period (i.e. only during the game) than home players, who are treated before they arrive, because they tend to live locally. In line with that, we find a slightly stronger effect when we control for PM at the visitor's location, see specification (3). ${ }^{22}$

In specification (4), which is our preferred specification, we also control for weather conditions. As the Netherlands is small, it appears that these additional control variables do not have any effect on the estimated effect of PM. In the last two specifications, we further investigate the effect of PM on the previous day, as well as on the next day. In specification (5), we find a small positive effect of lagged PM (about half), but no effect for lagged visitors PM when we do not control for PM on the day itself. In specification (6) we show that this lagged PM effect is spurious (and entirely due to positive autocorrelation of PM). Specification (6) includes two additional placebo variables, PM and visitor PM on the next day, which are both highly statistically insignificant.

One may argue that our results are driven by reduced cognitive ability and not by reduced risk taking. This could be the case if PM reduces the playing strength of chess players (which

\footnotetext{
${ }^{21}$ We have also estimated models with different restrictions on the distance between home and visitors team locations. The results are not sensitive to that.

${ }^{22}$ Consistent with this reasoning, the point estimate of visitor's PM is negative (but not statistically significant).
} 
is very plausible) and the probability of a draw depends on players' strength. To examine the latter, we first show in Figure A1b in the Appendix the probability of a draw as a function of the players' rating. It clearly shows that the probability of a draw does not depend on the rating level, except for low (below 1800) and high ratings (above 2350), which occur infrequent in our data (in less than $14 \%$ of the data). This figure is slightly misleading as it ignores that the players' probability of a draw does not only depend on the player's rating, but also on the opponent's rating (and the opponents' ratings are positively correlated). We therefore show Figure A2 in the Appendix, where we show the effect of the rating on the probability of a draw, while controlling for the difference in rating between opponents. This figure confirms the previous message and even shows that there is only an effect of rating for players with a rating above 2350, which occur seldom in our data (less than 9 percent). Hence, our estimates may be slight underestimates. Notice however, that the effect of mean rating is very small, implying that even if the stronger player would play much weaker, the underestimate is still negligible.

For policy, an important question is whether the marginal effect of PM is constant, as implied by the linear specification. ${ }^{23}$ We investigate this in several ways. An analysis using dummy indicators suggests a linear response. This is confirmed by an analysis using polynomials, see Table B1 in Appendix B. These estimates imply that the marginal effect is constant (i.e. the quadratic term is highly insignificant, whereas the linear term remains statistically significant). Hence, we do not reject linearity.

In conclusion, we find robust evidence of the effect of PM for a range of specifications, whereas placebo tests confirm that these results are unlikely by chance. Furthermore, we have demonstrated that this effect captures a reduction in risk-taking and cannot be explained by the alternative hypothesis that players make more draws because of weaker play. If anything,

\footnotetext{
${ }^{23}$ On theoretical grounds, one may expect a convex function, for example as PM has to surpass a certain threshold, or a concave function, for example because a saturation level of PM kicks in.
} 


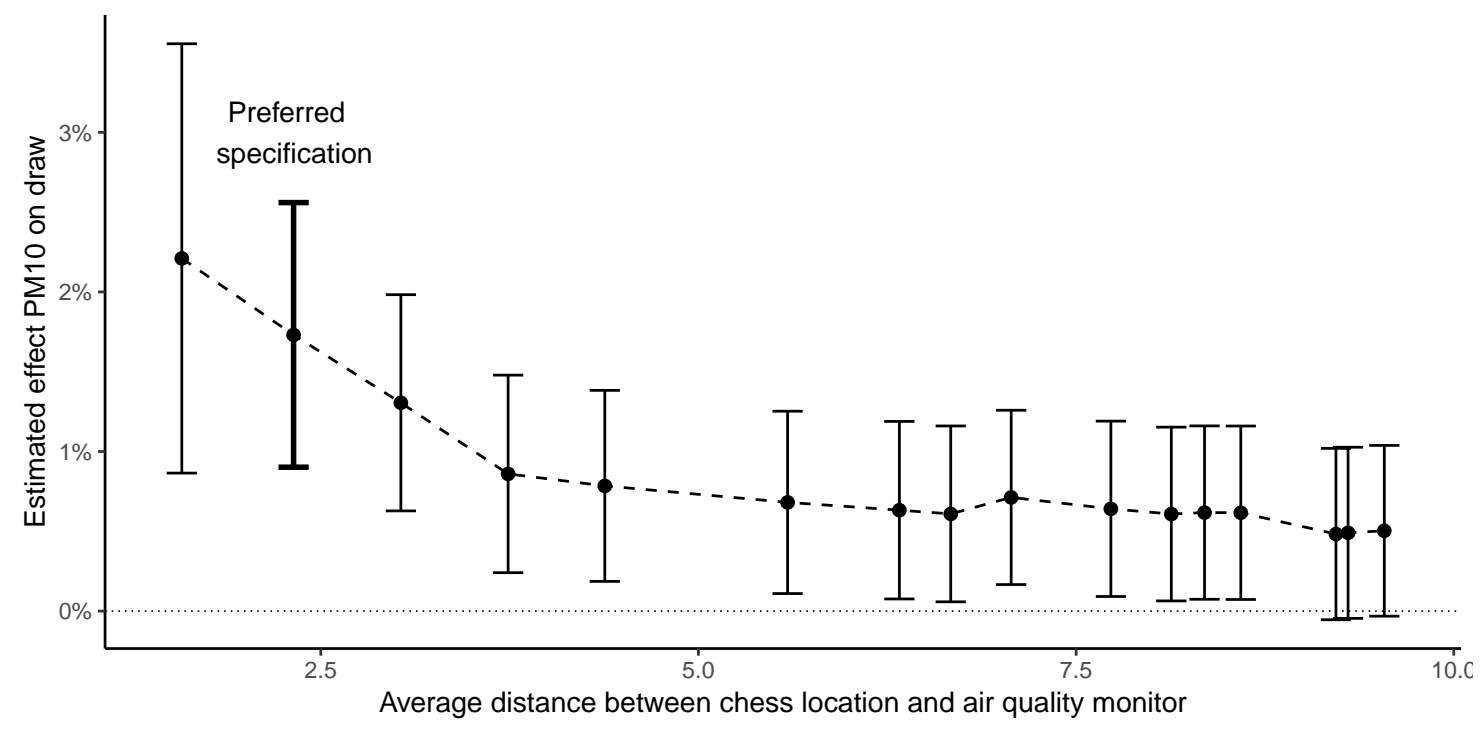

Figure 2: Sensitivity to distance between chess game and air quality monitoring station (error bars indicate $95 \%$ confidence intervals).

our estimates are underestimates of the true effect.

\subsection{Sensitivity analysis}

\subsubsection{Distance to the PM monitor}

We perform several other analyses to examine the robustness of our results to measurement error induced by the distance between the chess location and PM monitor. In particular, we have examined how the results in Table (2) change when we depart from $5 \mathrm{~km}$ as maximum distance between chess location and PM monitor stations. The $5 \mathrm{~km}$ maximum distance implies an average distance of about $2.3 \mathrm{~km}$, see Figure 2. It shows that the PM point estimate becomes smaller if we increase the maximally allowed distance, and therefore the average distance. Conversely, the coefficient increases if we reduce the maximum distance, but the confidence interval also increases because of the reduction in observations. Hence, our preferred specification is a conservative estimate of the effect of PM on risk taking. 
Table 3: Regression results using ELO subsamples.

\begin{tabular}{lcccccc}
\hline \hline & \multicolumn{7}{c}{ Draw } \\
\cline { 2 - 7 } & $(1)$ & $(2)$ & $(3)$ & $(4)$ & $(5)$ & $(6)$ \\
\hline $\mathrm{PM}_{10}$ & 0.0132 & $0.0266^{* * *}$ & 0.0100 & 0.0132 & $0.0255^{* * *}$ & 0.0101 \\
& $(0.0115)$ & $(0.0081)$ & $(0.0096)$ & $(0.0115)$ & $(0.0081)$ & $(0.0097)$ \\
$\mathrm{PM}_{10}$ (visitors) & 0.0006 & $-0.0149^{*}$ & 0.0042 & & & \\
& $(0.0095)$ & $(0.0082)$ & $(0.0114)$ & & & \\
Mean rating (100 points) & -0.0023 & 0.0049 & $0.0419^{* * *}$ & -0.0023 & 0.0046 & $0.0419^{* * *}$ \\
& $(0.0128)$ & $(0.0103)$ & $(0.0111)$ & $(0.0128)$ & $(0.0103)$ & $(0.0111)$ \\
Abs. diff. rating (100 points) & $-0.0414^{* * *}$ & $-0.0460^{* * *}$ & $-0.0698^{* * *}$ & $-0.0415^{* * *}$ & $-0.0460^{* * *}$ & $-0.0697^{* * *}$ \\
& $(0.0067)$ & $(0.0058)$ & $(0.0081)$ & $(0.0067)$ & $(0.0058)$ & $(0.0081)$ \\
Loc. \& Club FE & Yes & Yes & Yes & Yes & Yes & Yes \\
Day FE & Yes & Yes & Yes & Yes & Yes & Yes \\
Weather dummies & Yes & Yes & Yes & Yes & Yes & Yes \\
ELO subsample & $<2000$ & $2000-2200$ & $>2200$ & $<2000$ & $2000-2200$ & $>2200$ \\
Clusters & 883 & 1009 & 760 & 883 & 1009 & 760 \\
Observations & 4,942 & 8,191 & 4,322 & 4,942 & 8,191 & 4,322 \\
$\mathrm{R}^{2}$ & 0.1000 & 0.0680 & 0.1118 & 0.1000 & 0.0677 & 0.1117 \\
\hline
\end{tabular}

Notes: $\mathrm{PM}_{10}$ rescaled to $10 \mu \mathrm{g} / \mathrm{m}^{3}$. Location fixed effects are at the level of a monitoring station. Club fixed effects contain separate controls for playing at home or as visitor. Robust standard errors are clustered at the day $\times$ monitoring station. ${ }^{* * *},{ }^{* *},{ }^{*}$ indicate significance at $1 \%, 5 \%$, and $10 \%$.

\subsubsection{Heterogeneity}

One relevant sensitivity analysis is to distinguish between the effects of different rating levels.

In Table 3, using our preferred specification, it is shown that the point estimates are positive when we distinguish between three rating subgroups (see the first three specifications), but we do not have enough power to distinguish between the PM effect of these subgroups. These estimates also confirm that, except for the subgroup of strongest players, there is no effect mean rating, and therefore of players' strength, on the probability to make a draw. Consequently, one may argue that the estimates based on samples excluding the strongest players subgroup are more accurate if one is interested in the effect of PM on risk outcomes. If one accepts this view, then the estimated effect in Table 2 is a slight underestimate of the effective PM on risk-taking. We come to the same conclusion if we do not control for visitors PM (see the last three specifications). 
Table 4: Regression results for game outcomes.

\begin{tabular}{|c|c|c|c|c|c|}
\hline & Draw & Stronger wins & Weaker wins & Home wins & Away wins \\
\hline & $(1)$ & $(2)$ & $(3)$ & $(4)$ & $(5)$ \\
\hline $\mathrm{PM}_{10}$ & $\begin{array}{c}0.0183^{* * *} \\
(0.0050)\end{array}$ & $\begin{array}{c}-0.0118^{* * *} \\
(0.0044)\end{array}$ & $\begin{array}{l}-0.0062 \\
(0.0040)\end{array}$ & $\begin{array}{c}-0.0172^{* * *} \\
(0.0056)\end{array}$ & $\begin{array}{l}-0.0011 \\
(0.0061)\end{array}$ \\
\hline Mean rating (100 points) & $\begin{array}{c}0.0081^{* * *} \\
(0.0027)\end{array}$ & $\begin{array}{c}0.0000 \\
(0.0028)\end{array}$ & $\begin{array}{c}-0.0080^{* * * *} \\
(0.0022)\end{array}$ & $\begin{array}{c}-0.0111^{* * *} \\
(0.0028)\end{array}$ & $\begin{array}{c}0.0030 \\
(0.0028)\end{array}$ \\
\hline Abs. diff. rating (100 points) & $\begin{array}{c}-0.0507^{* * *} \\
(0.0033)\end{array}$ & $\begin{array}{c}0.1265^{* * *} \\
(0.0036)\end{array}$ & $\begin{array}{c}-0.0732^{* * *} \\
(0.0026)\end{array}$ & $\begin{array}{c}0.0407^{* * *} \\
(0.0044)\end{array}$ & $\begin{array}{l}0.0100^{* *} \\
(0.0041)\end{array}$ \\
\hline Loc. \& Club FE & Yes & Yes & Yes & Yes & Yes \\
\hline Day FE & Yes & Yes & Yes & Yes & Yes \\
\hline Clusters & 1137 & 1137 & 1137 & 1137 & 1137 \\
\hline Observations & 19,763 & 19,763 & 19,763 & 19,763 & 19,763 \\
\hline $\mathrm{R}^{2}$ & 0.0378 & 0.0797 & 0.0551 & 0.0405 & 0.0327 \\
\hline
\end{tabular}

Notes: .. ${ }^{* * *},{ }^{* *},{ }^{*}$ indicate significance at $1 \%, 5 \%$, and $10 \%$.

Another form of heterogeneity that may be interesting to examine, is whether the effect of the PM varies between players, because PM exacerbates existing stress levels. We cannot directly test this. However, it may be the case that stress levels are related to the difference in ratings between players. Additional analysis indicates that the marginal effects of PM does not depend on the Elo rating difference. ${ }^{24}$

\subsubsection{Other dependent variables}

In Table 4 we perform consistency checks by analysing the effect of PM on the probability that the stronger player wins and on the probability that the weaker player wins using linear probability models. ${ }^{25}$ Given the reasonable assumption that players maximize expected outcome (and hence their rating) the stronger players win less due to PM (because the stronger player reduces the outcome variance by taking less risk, which comes at the cost of having fewer wins). Additionally, the weaker player cannot win more due to PM (because

\footnotetext{
${ }^{24}$ We have also estimated logit models using the same specification. The average marginal effects are almost identical to those in the linear model. Because the difference in Elo ratings between players strongly reduces the probability of a draw, the relative effect of PM becomes stronger when the absolute difference in Elo ratings increases.

${ }^{25}$ We have also estimated a multinomial logit models with three outcomes (stronger player wins, draw, weaker player wins). Results are almost identical to the results in Table 4.
} 
a draw exceeds the expected outcome for this player). This assumption also implies that the stronger player's effect on the probability of winning must be stronger than the weaker player's effect on the probability of winning in absolute value, i.e. increased number of draws should mainly come at the cost of the strongest player's wins (otherwise taking less risk as the stronger player would be a dominant strategy i.e. less risk and more wins). ${ }^{26}$ Columns (2) and (3) confirm these predictions and support our claim that PM induces less risk taking. It may even suggest that people take less risk than is rational, in line with Duflo and Banerjee (2011), or at least take less risk than what they would prefer without PM.

In columns (4) and (5) we test whether there is a difference of the PM effect for home and visiting players. It appears that home players are affected more strongly by PM pollution. This makes sense and suggests that PM exposure prior to the game (but on the same day) has a detrimental effect in addition to the exposure during the game itself.

Finally, for games played in the highest league (about 10 percent of our sample), we know the moves. This offers alternative ways of doing a sensitivity analysis, because if PM induces players to make more draws, then it must be true that they either play less risky moves or they are more likely to agree to a draw (which nullifies the risk of losing), which will result in shorter games (i.e. games with less moves), given higher levels of PM. We find evidence of both mechanisms. ${ }^{27}$ However, the results are not robust with respect to specification (e.g. controlling for weather) and sample selection, which is not surprising given that we have a small subsample. Most importantly, for all specifications, we either find no effect (due to large standard errors), or we find statistically significant results that support that PM reduces risk taking.

\footnotetext{
${ }^{26}$ Conversely, the weaker player should not win more often due to PM. It is however possible that there is no effect on the number of wins of weaker player, as increased draws are favourable for the weaker player.

${ }^{27}$ We have classified risky play using several measures distinguishing between opening risk, where risk is based on the opening's share of draws, opposite castling, and white plays G4 in the opening. We also demonstrate that these measures are valid measures of risk taking as they are strongly related to the probability of making a draw. Results can be received upon request.
} 


\section{Conclusion}

Air pollution has been shown to affect cognitive ability and is hypothesized to decrease individual's risk taking. This hypothesis emerged from earlier literature that finds detrimental effects of particulate matter on composite decision outcomes (e.g. stock market returns in Heyes et al., 2016). Because it is unclear which mechanism drives these results, in this paper, we focus specifically on risk taking using the game of chess as a natural experiment.

We estimate the effect of PM on the probability that chess players make a draw, which directly reflects the variance of game outcomes, and is a clean indicator for risk taking. We use information from the Dutch national team league, where games are played at the same time in different locations. This setting comes close to the ideal experimental setup, as air pollution levels vary over time and space.

Our results show that PM induces chess players to make more draws. We find that A $10 \mu \mathrm{g}$ increase in $\mathrm{PM}_{10}$ (33.6\% of mean concentration) leads to a $5.8 \%$ increase in draws. We do not find any effect of PM when measured at the location of the visiting club, or of effects of PM on previous days, which implies that the PM effect is immediate. Our results demonstrate that air pollution reduces risk taking.

\section{References}

Archsmith, J., A. Heyes, and S. Saberian (2018). Air quality and error quantity: Pollution and performance in a high-skilled, quality-focused occupation. Journal of the Association of Environmental and Resource Economists 5(4), 827-863.

Barbosa, C. M. G., M. Terra-Filho, A. L. P. de Albuquerque, D. Di Giorgi, C. Grupi, C. E. Negrao, M. U. P. B. Rondon, D. G. Martinez, T. Marcourakis, F. A. dos Santos, et al. (2012). Burnt sugarcane harvesting-cardiovascular effects on a group of healthy workers, brazil. PloS one 7(9).

Beach, B. and W. W. Hanlon (2018). Coal smoke and mortality in an early industrial economy. The Economic Journal 128(615), 2652-2675.

Bondy, M., S. Roth, and L. Sager (2019). Crime is in the air: The contemporaneous re- 
lationship between air pollution and crime. Journal of the Association of Environmental and Resource Economists.

Burkhardt, J., J. Bayham, A. Wilson, E. Carter, J. D. Berman, K. O’Dell, B. Ford, E. V. Fischer, and J. R. Pierce (2019). The effect of pollution on crime: Evidence from data on particulate matter and ozone. Journal of Environmental Economics and Management 98, 102267.

Cameron, A. C. and P. K. Trivedi (2005). Microeconometrics: methods and applications. Cambridge University Press.

Chang, T., J. Graff Zivin, T. Gross, and M. Neidell (2016). Particulate pollution and the productivity of pear packers. American Economic Journal: Economic Policy 8(3), 141-69.

Chang, T. Y., J. Graff Zivin, T. Gross, and M. Neidell (2019). The effect of pollution on worker productivity: evidence from call center workers in china. American Economic Journal: Applied Economics 11(1), 151-72.

Chang, T. Y., W. Huang, and Y. Wang (2018). Something in the air: Pollution and the demand for health insurance. The Review of Economic Studies 85(3), 1609-1634.

Chappie, M. and L. Lave (1982). The health effects of air pollution: a reanalysis. Journal of Urban Economics 12(3), 346-376.

Chew, S. H., W. Huang, and X. Li (2019). Does haze cloud decision making? a natural laboratory experiment. A Natural Laboratory Experiment (July 20, 2019).

de Chaisemartin, C. and X. d'Haultfoeuille (2020). Two-way fixed effects estimators with heterogeneous treatment effects. American Economic Review forthcoming.

Duflo, E. and A. Banerjee (2011). Poor economics. PublicAffairs.

Ebenstein, A., V. Lavy, and S. Roth (2016). The long-run economic consequences of highstakes examinations: Evidence from transitory variation in pollution. American Economic Journal: Applied Economics 8(4), 36-65.

Graff Zivin, J. and M. Neidell (2012). The impact of pollution on worker productivity. American Economic Review 102(7), 3652-3673.

Graff Zivin, J. and M. Neidell (2018). Air pollution's hidden impacts. Science 359(6371), 39-40.

Hamanaka, R. B. and G. M. Mutlu (2018). Particulate matter air pollution: effects on the cardiovascular system. Frontiers in Endocrinology 9, 680.

Herrnstadt, E., A. Heyes, E. Muehlegger, and S. Saberian (2016). Air pollution as a cause of violent crime: Evidence from los angeles and chicago. Manuscript in preparation. 
Heyes, A., M. Neidell, and S. Saberian (2016). The effect of air pollution on investor behavior: Evidence from the s\&p 500. Technical report, National Bureau of Economic Research.

Heyes, A. and S. Saberian (2019). Temperature and decisions: evidence from 207,000 court cases. American Economic Journal: Applied Economics 11(2), 238-65.

Huang, J., N. Xu, and H. Yu (2017). Pollution and performance: Do investors make worse trades on hazy days? Available at SSRN 2846165.

Jans, J., P. Johansson, and J. P. Nilsson (2018). Economic status, air quality, and child health: Evidence from inversion episodes. Journal of Health Economics 61, 220-232.

Kahn, M. E. and P. Li (2019). The effect of pollution and heat on high skill public sector worker productivity in china. Technical report, National Bureau of Economic Research.

Klingen, J. and J. van Ommeren (2020). Urban air pollution and time losses: Evidence from cyclists in london. Regional Science and Urban Economics 81 (103504).

Künn, S., J. Palacios, and N. Pestel (2019). The impact of indoor climate on human cognition: Evidence from chess tournaments.

Li, H., J. Cai, R. Chen, Z. Zhao, Z. Ying, L. Wang, J. Chen, K. Hao, P. L. Kinney, H. Chen, et al. (2017). Particulate matter exposure and stress hormone levels: a randomized, double-blind, crossover trial of air purification. Circulation 136(7), 618-627.

Lichter, A., N. Pestel, and E. Sommer (2017). Productivity effects of air pollution: Evidence from professional soccer. Labour Economics 48, 54-66.

Lu, J. G. (2019). Air pollution: A systematic review of its psychological, economic, and social effects. Current opinion in psychology.

Netherlands National Institute for Public Health and the Environment (2019). Luch gevalideerde data. Bilthoven, Netherlands. retrieved from https://www.rivm.nl/lucht/ gevalideerde-data.

Regan, K. W. and G. M. Haworth (2011). Intrinsic chess ratings.

Royal Netherlands Meteorological Institute (2019). Daggegevens van het weer in nederland. De Bilt, Netherlands. retrieved from https://www.knmi.nl/nederland-nu/ klimatologie/daggegevens.

Sager, L. (2019). Estimating the effect of air pollution on road safety using atmospheric temperature inversions. Journal of Environmental Economics and Management 98, 102250.

Wang, X. (2017). An empirical study of the impacts of ambient temperature on risk taking. Psychology 8(07), 1053. 


\section{A. Additional descriptives}

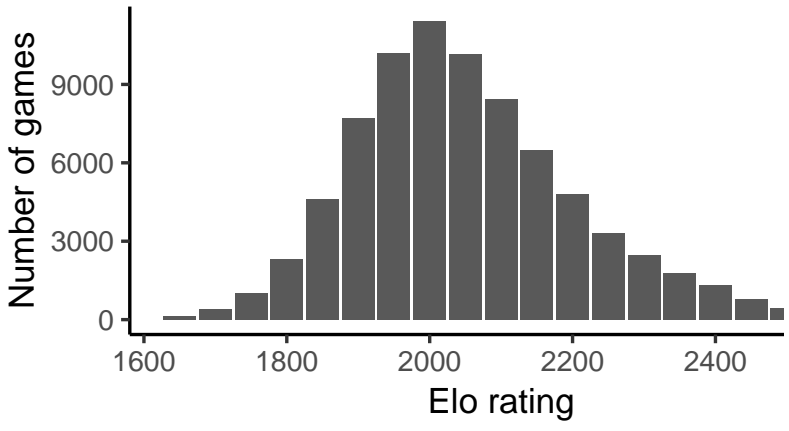

(a) Histogram of Elo rating.

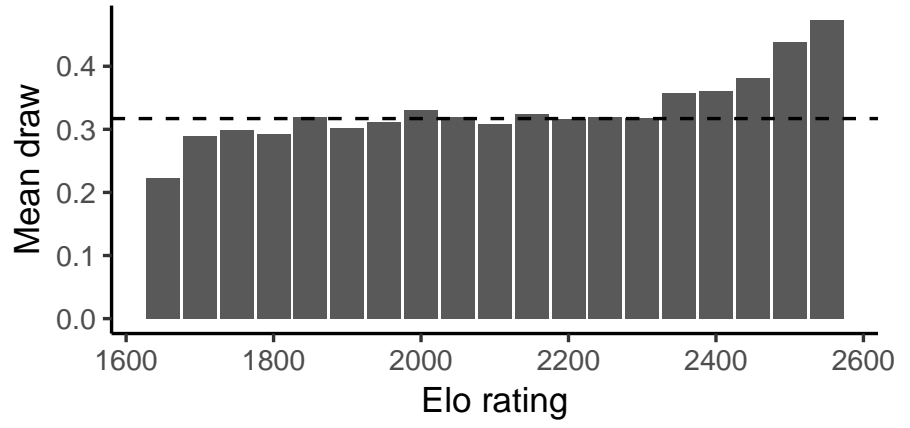

(b) Draw as a function of rating.

Figure A1: Frequency of Elo rating and draw per rating.

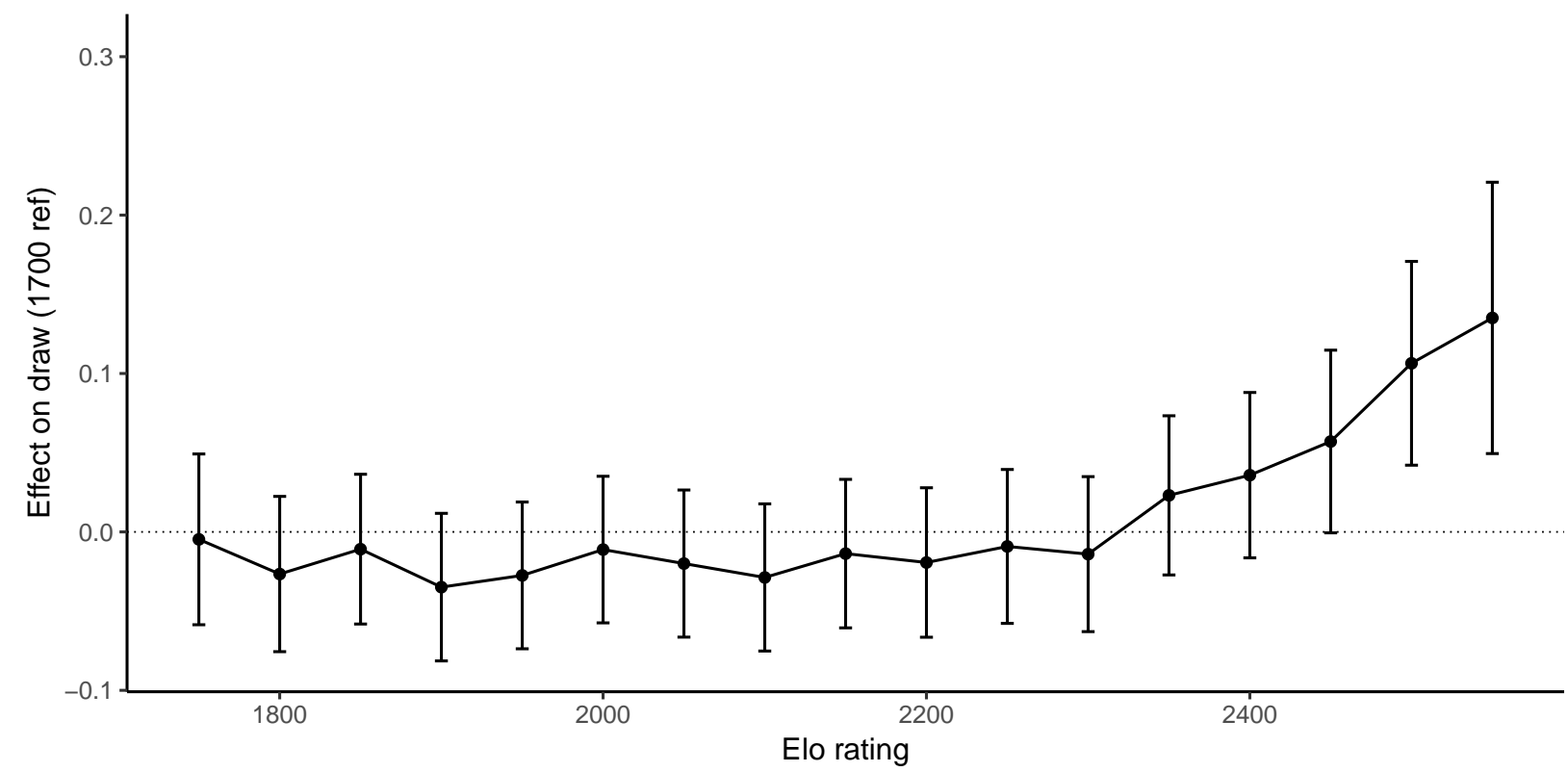

Figure A2: Effect of players strength (mean rating per game) on draw, conditional on difference in rating. 


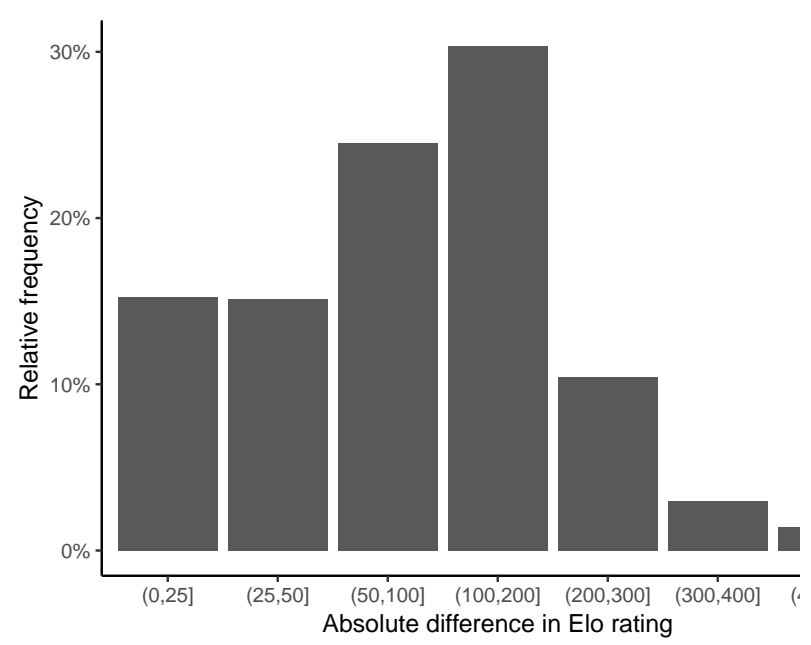

(a) Histogram of difference in rating

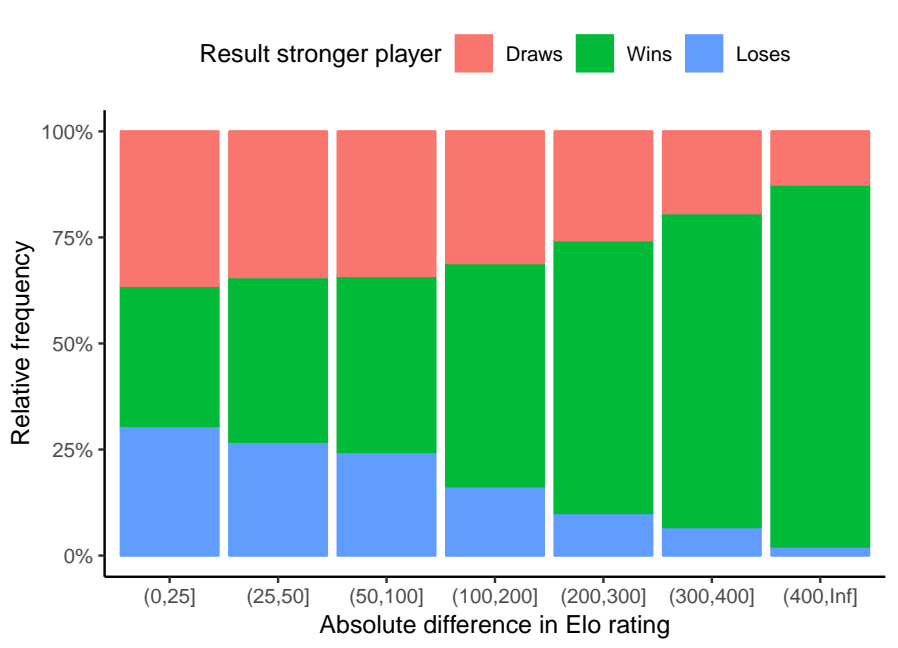

(b) Results player with highest rating

Figure A3: Histogram difference in rating and results stronger player. 


\section{B. Additional results}

Table B1: Regression results with higher order polynomial terms.

\begin{tabular}{|c|c|c|c|}
\hline & \multicolumn{3}{|c|}{ Draw } \\
\hline & $(1)$ & $(2)$ & $(3)$ \\
\hline $\mathrm{PM}_{10}$ & $\begin{array}{c}0.0183^{* * *} \\
(0.0050)\end{array}$ & $\begin{array}{c}0.0243^{* *} \\
(0.0115)\end{array}$ & $\begin{array}{c}0.0173 \\
(0.0252)\end{array}$ \\
\hline$\left(\mathrm{PM}_{10}\right)^{2}$ & & $\begin{array}{l}-0.0006 \\
(0.0009)\end{array}$ & $\begin{array}{c}0.0009 \\
(0.0045)\end{array}$ \\
\hline$\left(\mathrm{PM}_{10}\right)^{3}$ & & & $\begin{array}{l}-0.0001 \\
(0.0002)\end{array}$ \\
\hline Mean rating (100 points) & $\begin{array}{c}0.0081^{* * *} \\
(0.0027)\end{array}$ & $\begin{array}{c}0.0081^{* * *} \\
(0.0027)\end{array}$ & $\begin{array}{c}0.0081^{* * *} \\
(0.0027)\end{array}$ \\
\hline Abs. diff. rating (100 points) & $\begin{array}{c}-0.0507^{* * *} \\
(0.0033)\end{array}$ & $\begin{array}{c}-0.0507^{* * *} \\
(0.0033)\end{array}$ & $\begin{array}{c}-0.0507^{* * *} \\
(0.0033)\end{array}$ \\
\hline $\begin{array}{l}\text { Loc. \& team FE } \\
\text { Player FE }\end{array}$ & Yes & Yes & Yes \\
\hline Elo dummies & & & \\
\hline Weather dummies & Yes & Yes & $\begin{array}{l}\text { Yes } \\
\text { Yes }\end{array}$ \\
\hline Day FE & Yes & Yes & $\begin{array}{l}\text { Yes } \\
1137\end{array}$ \\
\hline Clusters & 1137 & 1137 & 1137 \\
\hline Observations & 19,763 & 19,763 & 19,763 \\
\hline $\mathrm{R}^{2}$ & 0.0378 & 0.0378 & 0.0378 \\
\hline
\end{tabular}

Notes: $\mathrm{PM}_{10}$ variables are rescaled to $10 \mu \mathrm{g} / \mathrm{m}^{3}$. Location fixed effects are at the level of a monitoring station. Club fixed effects contain separate controls for playing at home or as visitor. Robust standard errors in parentheses are clustered at the level of day $\times$ monitoring station. ${ }^{* * *},{ }^{* *},{ }^{*}$ indicate significance at $1 \%, 5 \%$, and $10 \%$. 